\title{
Ritter, Romance, Rewriting. Überlegungen zur dänischen Erzählliteratur in der Frühdruckzeit am Beispiel der Historie von Persenober oc Constantianobis (1572)
}

\begin{abstract}
Persenober oc Constantianobis, published in 1572 by Laurentz Benedicht in Copenhagen, is an early modern Danish translation and adaption of the Old French 'roman courtois' Partonopeu de Blois (twelfth century). This article outlines the way in which different forms of transformation and rewriting, or Retextualisierung (Joachim Bumke), have been realized in this edition. Another, now lost, edition from 1560, as well as a manuscript in Old Danish from ca. 1500 , originally derived from the Partalopa saga, which is a thirteenth- or fourteenth-century Old Norse-Icelandic prose adaption of the French romance, can be considered as precursors in this complex process of translation, adaptation and rewriting. The 1572 edition, the oldest complete Danish version in print, reveals some characteristics of paratextual and rewriting which seem to be unique in the Danish transmission: an epilogue and the transformation of an important passage (the first meeting between Persenober/Partonopeu and the princess Constantianobis/Melior) that strengthens the importance of the moral choices of the noble protagonists. Thus, the narrative can offer both nutz und kurtzweyl (usefulness and entertainment) and models for identification to its (mostly aristocratic) readership in sixteenth-century Denmark.
\end{abstract}

Der 1572 beim Kopenhagener Buchdrucker Laurentz Benedicht erschienene dänische Druck der Historie von Persenober oc Constantianobis ist die früheste erhaltene gedruckte dänische Übersetzung und Bearbeitung des ursprünglich altfranzösischen 'roman courtois' von Partonopeu de Blois (12. Jahrhundert). Im Folgenden sollen unterschiedliche Darstellungsformen von Transformation, rewriting oder Retextualisierung (Joachim Bumke) in diesem dänischen Frühdruck erläutert werden. Seine Vorgängertexte - ein nicht erhaltener früherer Druck von 1560 sowie ein dänisches Manuskript von ca. 1500, das auf die altnorwegisch-isländische Partalopa saga zurückgeht, eine im 13. oder 14. Jahrhundert entstandene Prosaübersetzung und Adaption des altfranzösischen Versromans - werden ebenfalls in die Untersuchung miteinbezogen. Der dänische Druck von 1572 weist einige Besonderheiten hinsichtlich der Paratexte und Formen von rewriting auf, die als einzigartig in der dänischen Überlieferungsgeschichte der Erzählung anzusehen sind: eine Nachschrift und insbesondere textuelle Veränderungen in einer zentralen Passage (welche die erste Begegnung des Protagonistenpaares betrifft). Insbesondere durch letzteres Verfahren wird dem Text ein deutlich moralisierender Duktus verliehen, der ihn mit einem sowohl nutz als auch kurtzweyl vermittelnden Identifikationsangebot für seine (vorwiegend adlige) Leserschaft im vormodernen Dänemark ausstattet.

Anna Katharina Richter, Universität Zürich

Ә Open Access. (C) 2019 Anna Katharina Richter, published by De Gruyter. (cc) BY-NC-ND This work is licensed under a Creative Commons Attribution-NonCommercial-NoDerivatives 4.0 International License. https://doi.org/10.1515/9783110563016-012 


\section{Dänische Partonopeu-Fassungen}

1572 erschien beim Kopenhagener Buchdrucker Laurentz Benedicht ein Büchlein im Oktavformat mit dem Titel:

Persenober. En lystig oc skøn Historie paa Riim/ om Konning Persenober oc Drotning Constantianobis. Lystig at høre oc læse. Nu nylige offuerseet oc Corrigerit/ Rettere end hun vaar før. Prentet i Kiøbenhaffn/ aff Laurentz Benedicht. 1572. ${ }^{1}$

(Persenober. Eine unterhaltsame und schöne Historie in Versen/ über König Persenober und Königin Constantianobis. Vergnüglich zu hören und zu lesen. Nun unlängst durchgesehen und korrigiert/ richtiger als sie zuvor war. Gedruckt in Kopenhagen/ von Laurentz Benedicht. 1572.)

Es handelt sich hierbei um eine frühneuzeitliche dänische Bearbeitung des anonymen französischen Versromans Partonopeu de Blois, welcher nach bisherigem allgemeinem Forschungskonsens in den Jahren 1180-1185, möglicherweise jedoch, wie jüngere Arbeiten zeigen, schon einige Jahre früher (1170-80), verfasst wurde ${ }^{3}$ und mit zahlreichen Übersetzungen und Bearbeitungen in vielen europäischen Sprachen zu einer der beliebtesten und sehr weit verbreiteten mittelalterlichen Erzählungen gehörte. ${ }^{4}$ Der französische Erzählstoff ist vermutlich über eine norwegisch-isländische Prosabearbeitung nach Dänemark gekommen. ${ }^{5}$ Diese heute nicht mehr bekannte Fassung war aller Voraussicht nach sowohl die Vorlage für die gedruckte Überlieferung der Erzählung als auch für die einzig bekannte Handschrift des Textes, die im Manuskript Codex Holmiensis K 47 (Königliche Bibliothek Stockholm) zusammen mit fünf anderen höfischen Versromanen in dänischer Sprache überliefert ist. ${ }^{6}$ Dieses Manuskript,

1 Königliche Bibliothek Kopenhagen, Sign. LN 1325, $8^{\circ}$. Vgl. auch die digitalisierte Edition auf Early European Books: https://search.proquest.com/eeb/docview/2090302028 (letzter Zugriff am 27.5.2019).

2 Diese und alle folgenden Übersetzungen aus den skandinavischen Sprachen von mir, AKR (sofern nicht anders angegeben).

3 Zur Datierungsfrage des Partonopeu-Romans vgl. Sif Rikhardsdottir, Medieval Translations and Cultural Discourse. The Movement of Texts in England, France and Scandinavia. Cambridge 2012, S. 118; sowie Penny Eley, Partonopeus de Blois. Romance in the Making. Cambridge 2011, S. 11-15.

4 Vgl. Birgit Nyborg (Hg.), Tre riddersagaer: Sagaen om Partalopi. Sagaen om Flores ok Blankiflor. Sagaen om Bevers. Oslo 2005, S. 54; und Rikhardsdottir (vgl. Anm. 3), S. 113-151.

5 Auf die komplexe Transmissionsgeschichte wird hier unten näher eingegangen.

6 Siehe hierzu die digitalisierte Edition von Jonathan Adams und Marita Akhøj Nielsen des in den Jahren 2002-2006 durchgeführten Forschungsprojekts von Det Danske Sprog- og Litteraturselskab (Gesellschaft für dänische Sprache und Literatur, DSL, welche der Universität Kopenhagen und der Königlichen Bibliothek angeschlossen ist): https://tekstnet.dk/manuscript-descriptions/stockholmk47 (Beschreibung der Handschrift Cod. Holm. K 47) sowie https://tekstnet.dk/persenober-og-kon stantianobis/1 (Edition). Zur Handschrift Cod. Holm. K 47 bemerken die Herausgeber: „Den tidligst kendte tekst af den danske Persenober og Konstantianobis findes i stockholmhåndskriftet $\mathrm{K} 47$ fra 


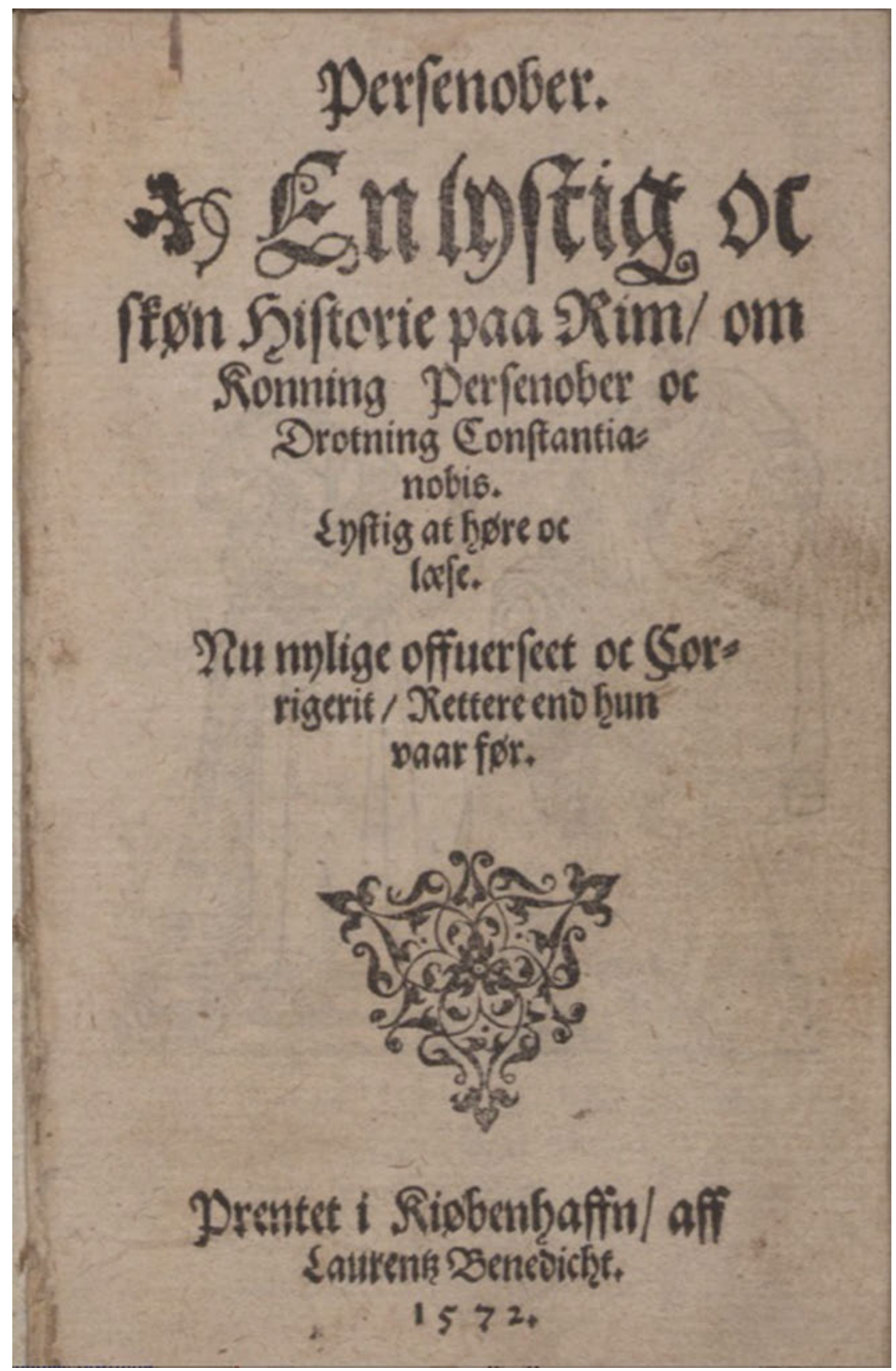

Abb. 1: Persenober oc Constantianobis, Kopenhagen 1572. Titelblatt (Bl. A1r) (@ Königliche Bibliothek Kopenhagen/Early European Books). 
vermutlich die Abschrift einer älteren Vorlage, ist auf das ausgehende 15. Jahrhundert oder um $1500 \mathrm{zu}$ datieren. ${ }^{7}$ Bei allen darin enthaltenen sechs Romanen handelt es sich um dänische Übersetzungen volkssprachlicher Vorlagen: Drei davon sind Übersetzungen und Bearbeitungen der berühmten Eufemiavisor (Eufemia-Lieder), nämlich Anfang des 14. Jahrhunderts auf Geheiß der norwegischen Königin Eufemia (Regierungszeit 1299-1313) ins Altschwedische übertragene höfische Erzählungen, welche ihrerseits teilweise altnorwegische, teilweise kontinentale (französische sowie deutsche) Vorlagen besitzen: Ivan Løveridder (Ivan Löwenritter, zurückgehend auf Chrétien de Troyes’ Yvain ou Le Chevalier au lion), Flores oc Blantzeflor (Flores und Blanzeflor, nach dem altfranzösischen Versroman Floire et Blancheflor) und Hertug Frederik af Normandi (Herzog Fredrik aus der Normandie, eine Erzählung aus dem Stoffkreis der matière de Bretagne). ${ }^{8}$ Die anderen drei Texte sind Persenober oc

ca. 1500. Sjuskefejl i teksten tyder afgjort på, at der er tale om en afskrift. Det underbygges af, at den ældste bevarede trykte udgave fra 1572 har læsemåder, som efter al sandsynlighed er oprindelige og går tilbage til et fælles forlæg for K 47 og trykkene. Blandt disse passager er den mest iøjnefaldende et helt vers, der mangler i $\mathrm{K} 47$, men dårligt kan undværes, fordi det indeholder rimordet til vers 1247.“ (Die früheste bekannte Textfassung des dänischen Persenober und Konstantianobis stellt die Handschrift Stockholm K 47 von ca. 1500 dar. Flüchtigkeitsfehler im Text deuten auf jeden Fall darauf hin, dass es sich hierbei um eine Abschrift handelt. Dafür spricht auch, dass der älteste erhaltene Druck von 1572 Lesarten aufweist, die aller Wahrscheinlichkeit nach auf eine gemeinsame Vorlage für K 47 und die Drucke zurückgehen. Am auffälligsten ist dabei ein Vers, der in K 47 fehlt, aber unverzichtbar ist, weil er das ergänzende Reimwort zu Vers 1247 enthält.).

7 Die Persenober-Erzählung datiert der Text selbst auf das Jahr 1484. Vgl. die ausführliche Beschreibung des Manuskripts unter https://tekstnet.dk/manuscript-descriptions/stock holm-k 47-lang-beskrivelse (letzter Zugriff am 27.5.2019).

$8 \mathrm{Zu}$ den schwedischen Eufemiavisor vgl. die kommentierte Edition: Eufemiavisoma. Bde. I (Flores och Blanzeflor. Hertig Fredrik av Normandie) und II (Ivan Lejonriddaren). Textredigering, kommentarer och ordförklaringar av Henrik Williams. Inledning av Bo Ralph. Stockholm 2018 (Svenska klassiker utgivna av Svenska Akademien); Gösta Holms, 'Eufemiavisorna'. In: Medieval Scandinavia: An Encyclopedia. Hg. v. Philip Pulsiano. New York 1993, S. 171-173; Jürg Glauser (Hg.), Skandinavische Literaturgeschichte. 2. Aufl. Stuttgart, Weimar 2016, S. 30-31; Stefanie Würth, 'Eufemia. Deutsche Auftraggeberin schwedischer Literatur am norwegischen Hof. In: Arbeiten zur Skandinavistik. 13. Arbeitstagung der deutschsprachigen Skandinavistik 29.7.-3.8.1997 in Lysebu/Oslo. Hg. v. Fritz Paul. Frankfurt a. M. 2000 (Texte und Untersuchungen zur Germanistik und Skandinavistik 45), S. 269-281; und insbesondere den Sammelband von Olle Ferm et al. (Hgg.), The Eufemiavisor and Courtly Culture, Time, Texts and Cultural Transfer, Papers from a Symposium in Stockholm 11-13 October 2012. Stockholm, Kungliga Vitterhets Historie och Antikvitets Akademien 2015 (Konferenser 88). - Zum Manuskript Cod. Holm. K 47 siehe insbesondere Jürg Glauser, 'Höfisch-ritterliche Epik in Dänemark zwischen Spätmittelalter und Frühneuzeit'. In: Festschrift für Oskar Bandle zum 60. Geburtstag am 11. Januar 1986. Hg. von Hans-Peter Naumann unter Mitwirkung von Magnus von Platen und Stefan Sonderegger. Basel, Frankfurt a. M. 1986 (Beiträge zur nordischen Philologie 15), S. 191-207. 
Constantianobis sowie Dværgekongen Laurin (Zwergenkönig Laurin) und Den kyske Dronning (Die keusche Königin). Die Historie von Persenober steht in dieser Handschrift genau in der Mitte, an vierter Stelle, auf Bll. $169^{\mathrm{v}}$ bis $196^{\mathrm{r}}$; sie leitet damit die zweite Hälfte der Ritterromane in diesem Manuskript ein, in denen die Liebe als zentrales Thema behandelt wird. ${ }^{9}$

Vor dem genannten Kopenhagener Druck von 1572 erschien bereits 1560 eine frühere Ausgabe, vermutlich ebenfalls in Kopenhagen, welche zwar nicht mehr erhalten ist, auf die der Benedicht-Druck von 1572 sowohl im Titel als auch am Ende seines eigentlichen Erzähltextes jedoch verweist. ${ }^{10}$ Noch ein weiterer, allerdings unvollständiger dänischer Druck aus dem späten 16. Jahrhundert ist überliefert, der auf die Zeit 1572-1600 datiert wird, diesmal vermutlich aus einer Offizin in Norddeutschland. ${ }^{11}$ Im Jahr 1700 scheint der letzte nachgewiesene Druck in Kopenhagen erschienen zu sein, wahrscheinlich gab es dazwischen noch die eine oder andere, nicht mehr erhaltene Ausgabe aus dem 17. Jahrhundert. ${ }^{12}$ Der Druck von 1572 stellt somit die älteste vollständig erhaltene Druckfassung des Textes in Dänemark dar.

\section{Höfische Literatur in der Frühdruckzeit in Dänemark}

In welchem literarhistorischen Kontext steht nun die Produktion eines Textes wie die dänischen Adaptionen des Partonopeu-Romans in ihrer handschriftlichen Fassung und ihren gedruckten Versionen? Nach der Einführung des Buchdrucks in Dänemark und Schweden in den letzten Jahrzehnten des 15. Jahrhunderts $^{13}$ druckte vor allem der aus den Niederlanden eingewanderte,

9 Vgl. Glauser, 'Höfisch-ritterliche Epik' (Anm. 8), S. 192-193 und https://tekstnet.dk/perseno ber-og-konstantianobis/about\#K47ogPK (letzter Zugriff am 27.5.2019).

10 Vgl. J.P. Jacobsen et al. (Hgg.), Danske Folkebøger fra 16. og 17. Aarhundrede. Bd. VI. København 1925, S. 149- 207 (Text) und S. 511-513 (Bibliographie), im Folgenden mit DF VI abgekürzt. Zur Ausgabe von 1560 s. hier, S. 512. Der Verweis auf den Vorgängerdruck findet sich in der Ausgabe von 1572 auf Bl. D8r.

11 Diese Ausgabe befindet sich in der Königlichen Bibliothek Kopenhagen, Sign. LN 1325a $8^{\circ}$ und wird nicht in Danske Folkebøger erwähnt, vgl. DF VI, S. 511-513.

12 Die Ausgabe von 1700 befindet sich ebenfalls in der Königlichen Bibliothek Kopenhagen, Sign. Hielmst. $18658^{\circ}$. Vgl. auch die Angaben in $D F$ VI, S. 512.

131482 wurde in Odense von Johan Snell das erste Buch überhaupt in Dänemark gedruckt (Obsidionis Rhodiae urbis descriptio des Guillaume Caoursin), bereits zuvor druckte er dort wohl ein Messbuch (Breviarum Ottoniense, undatiert). Vgl. hierzu Glauser, Skandinavische Literaturgeschichte (Anm. 8), S. 55 und generell zum (frühen) Buchdruck in Dänemark auch Henrik 
ab 1489 in Kopenhagen tätige Gotfried von Ghemen (dän. Gotfred af Ghemen) als erster permanent etablierter dänischer Drucker neben Schriften für die 1479 gegründete Kopenhagener Universität auch volkssprachliche Texte. ${ }^{14}$ Das erste auf Dänisch gedruckte Buch in seiner Offizin war Den danske Rimkrønike (Die dänische Reimchronik) 1495, bald darauf folgten frühe Romane und andere Erzähltexte, die zumeist nach kontinentalen Textvorlagen bearbeitet und ins Dänische übersetzt wurden: Flores oc Blantzeflor (1504 und 1509), Jesu barndoms bog (Das Buch von der Kindheit Jesu, 1508), Karl Magnus krønike (Chronik von Karl dem Großen, 1509 und nochmals 1534). Weitere, bei verschiedenen Druckern in Kopenhagen und auch in Norddeutschland erschienene Erstdrucke dänischer früher Romane sind Griseldis (1528), Sigismunda (1528), Ion presth (dänische Version der Epistola presbiteri Johannis, 1510), Marcolfus (1540), En Ræffue Bog, som kaldes paa Tyske Reinicke Foss (Ein Fuchsbuch, das auf Deutsch Reinicke Fuchs heißt, 1555) und im Jahre 1560 dann der eingangs erwähnte, heute verlorene dänische (Erst?)Druck von Persenober oc Constantianobis, um nur einige Beispiele zu nennen. ${ }^{15}$ Die ,große Welle' gedruckter Übersetzungen meist (hoch- oder nieder-)deutscher Vorlagen von didaktischen und erzählenden Historienbüchern und Frühromanen setzt in Dänemark ab den 1530er Jahren ein. ${ }^{16}$ In der Regel im Oktavformat und ohne aufwendige Illustrationen gedruckt, waren sie von Beginn an für eine relativ kostengünstige Publikationsform vorgesehen, welche häufige Nachdrucke ermöglichte:

Bereits im 16. Jahrhundert verwendet man für diese Texte in der Regel kleinere Druckformate (meist Oktav), was belegt, dass von Anfang an eine Aufteilung des Gattungsspektrums auf Formate und Ausstattung vorgenommen wird: Neben großformatigen Prachtwerken mit repräsentativem Charakter (Bibeln, Chroniken usw.) gibt es handlichere Bücher für weniger öffentliche Lesesituationen. Die zahlreichen Drucke dieser Historienbücher, die oft in rascher Folge wieder aufgelegt wurden, zeigen, wie die neue Medialitätsform gleich nach der Einführung des Buchdrucks für die Erfahrung imaginärer Welten eingesetzt wird. ${ }^{17}$

Horstbøll, Menigmands medie. Det folkelige bogtryk i Danmark 1500-1840. København 1999 (Danish Humanist Texts and Studies 19).

14 Dazu Glauser, Skandinavische Literaturgeschichte (Anm. 8), S. 56.

15 Siehe dazu Glauser, Skandinavische Literaturgeschichte (Anm. 8), S. 31 und S. 59-60.

16 Vgl. hierzu Glauser, Skandinavische Literaturgeschichte (Anm. 8), S. 59-60 und Anna Katharina Richter, Transmissionsgeschichten. Untersuchungen zur dänischen und schwedischen Erzählprosa in der frühen Neuzeit. Tübingen, Basel 2009 (Beiträge zur nordischen Philologie 41), S. 17-22.

17 Glauser, Skandinavische Literaturgeschichte (Anm. 8), S. 60. [Anderswo in Westeuropa scheint ein Folio- oder Quartformat für frühe Romane geläufiger gewesen zu sein. Siehe für die Benutzung des Quartformats in England den Beitrag von Boffey (Seite 138), für die Verwendung des Folioformats bei französischen Artusromanen den Beitrag von Montorsi (Seite 174) 
Zahlreichen der oben genannten Texte ist gemeinsam, dass sie fremdsprachige, d. h. mittelalterliche kontinentaleuropäische (häufig deutsche oder französische) Übersetzungsvorlagen hatten. Viele dieser Erzählungen wurden um 1500 aus dem Hoch- oder Niederdeutschen übersetzt, doch nicht wenige weisen bereits eine ältere Transmission innerhalb Skandinaviens auf: Bereits im 13. und 14. Jahrhundert wurde nämlich in Norwegen und Island ein großes Textkorpus an altfranzösischen Erzählungen (Romane, fabliaux und lais) der matière de Bretagne, dazu die lais der Marie de France, Erzählungen aus der matière d'aventure wie auch aus der Gattung der französischen Heldensage (chansons de geste aus der matière de France) sowie Texte aus dem Anglonormannischen (etwa die Tristan-Erzählung) ins Altnorwegische übertragen. Bergen und Oslo stellten dabei Zentren dieser umfangreichen Vermittlertätigkeit dar, von denen aus die neuen Erzählformen und Genres wie Rittersagas (riddarasögur, romances), die eingangs erwähnten Eufemiavisor und auch die Balladen in die anderen nordischen Länder und Sprachen verbreitet wurden. In Schweden und in Dänemark wurden die höfischen Versromane dann im 14. und 15. Jahrhundert adaptiert, in Form von Bearbeitungen und Übersetzungen. ${ }^{18}$ Wurden jedoch Texte wie etwa die Karlamagnús saga (Saga von Karl dem Großen), eine Kompilation von Texten aus dem Karls-Kreis mit französischen und lateinischen Vorlagen, bereits im 13. Jahrhundert ins Altnorwegische und im 14. Jahrhundert ins Altschwedische übertragen, folgte Dänemark erst relativ spät mit der Adaption der mittelalterlich-höfischen Erzähltradition, nämlich ab ca. 1450. Es gibt nur sehr wenige literarische Textzeugnisse aus dieser Zeit, eines der wichtigsten ist die bereits erwähnte Handschrift Cod. Holm. K 47. ${ }^{19}$

und für die Buchformate in Augsburg bzw. im deutschen Südwesten den Beitrag von Bertelsmeier-Kierst (Seite 37) in diesem Band.]

18 Hierzu ausführlich Glauser, Skandinavische Literaturgeschichte (Anm. 8), S. 31 und Jürg Glauser, 'Romance (Translated riddarasögur)'. In: A Companion to Old Norse-Icelandic Literature and Culture. Hg. v. Rory McTurk. Oxford 2005, S. 372-387; sowie Marianne E. Kalinke, 'Norse Romance (Riddarasögur)'. In: Old Norse-Icelandic Literature. A Critical Guide. Hg. v. Carol J. Clover und John Lindow. Toronto u.a. 2005, S. 316-363.

19 Zur (verspäteten) Rezeption in Dänemark siehe Glauser, 'Höfisch-ritterliche Epik' (wie Anm. 8), S. 192. Studiert man das Textkorpus, das die Dänische Sprach- und Literaturgesellschaft im Rahmen des erwähnten Digitalisierungsprojekts als „Texte aus Dänemarks Mittelalter 1100-1550“ erarbeitet hat, wobei Handschriften wie Frühdrucke berücksichtigt wurden, ist die große Anzahl an Gesetzestexten auffallend, ebenso sind historische Texte wie Chroniken und religiöse Texte wie Legenden oder das sehr beliebte Buch von der Kindheit Jesu (Jesu barndoms bog, 1508) vertreten. Narrative Texte stellen insgesamt eher eine Untergruppe dar. Wie die dänische Literaturwissenschaftlerin Pil Dahlerup jedoch mit Verweis auf die Balladenrezeption und auf bildliche Darstellungen in Kirchen usw. vermutet, ist wohl anzunehmen, dass höfische Literatur auch schon früher bekannt war, wir jedoch keine Textzeugnisse aus dieser Zeit erhalten haben, 


\section{Die Transmission der Persenober-Historie und ihr europäischer Hintergrund}

Auch die Transmission der Persenober-Historie in Skandinavien verlief zunächst über eine Adaption und Übersetzung einer französischen Vorlage in einen altnorwegischen Prosatext: Die spätmittelalterliche Partalopa saga zählt zu den romances, den übersetzten riddarasögur (Rittersagas). Ihre Vorlage dürfte eine (eventuell verlorene) französische Textversion sein, die genaue Entstehungszeit der Saga ist jedoch unklar, entweder im 13. Jahrhundert am norwegischen Königshof (im Zuge der vorhin erwähnten ,Welle“ mit Übersetzungen aus dem Altfranzösischen, ähnlich wie in der Transmission von Flores oc Blantzeflor, der ja dann später mit Persenober auch im selben dänischen Manuskript Cod. Holm. K 47 enthalten ist) - oder etwas später, vor dem 14. Jahrhundert direkt auf Island. ${ }^{20}$

Die europäische Handschriftenüberlieferung des Partonopeu de Blois lässt sich in zwei Textgruppen unterscheiden: Ebenso wie das mittelenglische Fragment von ca. 1450, die dänische Handschrift Cod. Holm. K 47, die spanische Prosaversion und eine katalanische Übersetzung davon gehört auch die altnorwegische Partalopa saga zur sogenannten Z-Gruppe (hier beginnt die Erzählung in Griechenland, der ursprünglichen Heimat der Protagonistin Melior). ${ }^{21}$ Unterschieden davon

vgl. Pil Dahlerup, Dansk litteratur. Middelalder. Bd. II: Verdslig litteratur. København 1998, S. 265-267.

20 Die Saga ist in zwei Redaktionen, A und B, überliefert. Vgl. die maßgebliche Edition: Partalopa saga. Hg. v. Lise Præstgaard Andersen. Copenhagen 1983 (Editiones Arnamagnæanæ, Series B, Bd. 28). Marianne E. Kalinke verweist in dieser Diskussion auf die deutliche Bearbeitung des französischen Romans durch den Sagaautor (insbesondere das Motiv der maiden-king anstelle der Fee in der Figurendarstellung der Prinzessin Melior/Marmoria) und spricht sich für eine Entstehung der Saga in Island aus. Vgl. dazu Marianne E. Kalinke, 'Scribe, Redactor, Author: The Emergence and Evolution of Icelandic Romance'. In: Viking and Medieval Scandinavia 8 (2012), S. 171-198, hier insbesondere S. 186-189; vgl. dazu auch die Angaben bei Pulsiano (Anm. 8), S. 497 und Rikhardsdottir (vgl. Anm. 3), S. 21-22 und S. 116-120; sowie Marianne E. Kalinke, 'Clári saga, Hrólfs saga Gautrekssonar, and the Evolution of Icelandic Romance'. In: Riddarasogur. The Translation of European Court Culture in Medieval Scandinavia. Hg. v. Karl G. Johansson und Else Mundal. Oslo 2014, S. 273-292, hier S. 285.

21 Im französischen Text wird die weibliche Hauptfigur zunächst „une damoisele“ oder „la dame“ genannt, schließlich mit ihrem Namen, Melior. Als Textgrundlage für den französischen Roman dient die Ausgabe Le Roman de Partonopeu de Blois. Édition, traduction et introduction de la rédaction A (Paris, Bibliothèque de l'Arsenal, 2986) et de la Continuation du récit d'après les manuscrits de Berne (Burgerbibliothek, 113) et de Tours (Bibliothèque municipale, 939), par Olivier Collet et Pierre-Marie Joris. Paris 2005 (im Folgenden mit Le Roman abgekürzt). Zur Namensgebung vgl. Le Roman, V. 1129, V. 1243 und V. 1763). In der Partalopa saga heißt die Prinzessin Marmoria (vgl. Partalopa saga (vgl. Anm. 20), S. 1), im dänischen 
werden die Texte der sogenannten Y-Gruppe (hier beginnt die Geschichte in Frankreich, der Heimat von Partonopeu), nämlich der französische Versroman und die davon ausgehenden, mehr oder weniger direkten Übersetzungen des Textes ins Englische, ins Hoch- und Niederdeutsche, ins Niederländische und ins Italienische. ${ }^{22}$ In der Forschung wurde die Vermutung geäußert, dass der Druck aus Laurentz Benedichts Offizin von 1572, wohl auch der verlorene von 1560 sowie die in der Handschrift Cod. Holm. K 47 überlieferte Version des Textes möglicherweise letzten Endes auf eine gemeinsame, verlorene norwegisch-isländische Vorlage zurückgehen. In diesem Fall wäre das wohl eine Version der Partalopa saga, welche älter sein muss als die heute (wie häufig in der Überlieferung altnorwegischer und isländischer Texte des Mittelalters) allerdings nur noch in späteren Fassungen erhaltenen isländischen Handschriften dieser Saga, von denen die älteste das Manuskript AM $5334^{\text {to }}$ (Reykjavík, Stofnun Árna Magnússonar í íslenskum fræðum, ca. 1450-1500) ist. Es existierte jedoch bereits zuvor in der (verlorenen) Ormsbók aus dem 14. Jahrhundert ebenfalls eine Version der Partalopa saga. ${ }^{23}$ Möglicherweise hat es Varianten der Saga gegeben, die dem dänischen Persenober-Versroman näherstehen als die heute erhaltenen Sagamanuskripte. ${ }^{24}$ Vielleicht stellt die Version in Cod. Holm. K 47, die sich größtenteils an die Saga, teilweise wiederum enger an den französischen Text hält, aber auch eine eigene originale dänische Bearbeitung einer oralen Tradition dar, etwa wegen der zahlreichen eigenwilligen dänischen Eigennamen. ${ }^{25}$ Aufgrund der unklaren Quellenlage ist jedoch bei all

Manuskript Cod. Holm. K 47 sowie in den dänischen Drucken aber Constantianobis, vermutlich als Ableitung vom Namen ihrer Heimatstadt Konstantinopel, im dänischen Text Constantia. $\mathrm{Zu}$ dieser Variante (sowie zu den anderen Namensänderungen, etwa Meliors Schwester Urrake, die in der dänischen Tradierung zu Fraga/Frago wird), siehe DF VI, S. LXI.

$22 \mathrm{Zu}$ den Textgruppen vgl. Partalopa saga (vgl. Anm. 20), S. XIII-XIV sowie Kalinke, 'Scribe, Redactor, Author' (Anm. 20), S. 186.

23 Vgl. Partalopa saga (vgl. Anm. 20), S. XLVIII-LVLXV; Nyborg (vgl. Anm. 4), S. 56-58; Rikhardsdottir, (vgl. Anm. 3), S. 119-120; sowie Kalinke, 'Clári saga' (Anm. 20), S. 285.

24 Vgl. hierzu DF VI, S. LIX-LX und Nyborg (vgl. Anm. 4), S. 57.

25 Dies vermutet Dahlerup (vgl. Anm. 19), S. 270. Bereits der dänische Herausgeber des Versromans im 19. Jahrhundert, Carl Joakim Brandt, äußert sich zur eigenwilligen Namensgebung in der dänischen Tradierung („Constantianobis“ möglicherweise aufgrund eines Missverständnisses oder weil der dänische Bearbeiter um 1500 ihren Namen vergessen und sich einfach am Ortsnamen Konstantinopel, wo die Geschichte beginnt und wo ihr Vater regierender König ist, orientiert hätte). Vgl. Carl Joakim Brandt (Hg.), Romantisk Digtning fra Middelalderen. Bd. III. København 1877, S. 334. Klärungen zu der- resp. denjenigen genauen Textfassung(en), die der dänischen Tradierung (für Handschrift und Druck) zugrunde liegt resp. liegen, stehen noch aus, ebenso genauere Angaben zur Entstehung des Manuskripts Cod. Holm. K 47 selbst. 
diesen Überlegungen $\mathrm{zu}$ Vorlagen und wechselseitigen Abhängigkeiten der nordischen Persenober-Texte große Vorsicht geboten und es bedürfte einer detaillierten Untersuchung.

Vor diesem komplexen transmissionshistorischen Hintergrund und angesichts der Tatsache, dass die Frühdruckzeit in Skandinavien noch lange durchaus „von der Gleichzeitigkeit, dem Neben- und Miteinander und der Mischung der Überlieferungsträger Handschrift/Buchdruck geprägt “ ${ }^{26}$ war, ist auch der 1572 in Laurentz Benedichts Offizin erschienene PersenoberDruck zu betrachten. Wie auch immer die genaue Überlieferung des Textes im Norden verlaufen ist: Zusammen mit der bereits 1504 und 1509 gedruckten Erzählung von Flores oc Blantzeflor ${ }^{27}$ sowie der Karl Magnus Krønike (1509, 1534), beide bei Gotfred af Ghemen, stellt der Persenober jedenfalls einen der explizit höfischen Erzähltexte aus dem Mittelalter dar, die in der dänischen Frühdruckzeit des 16. Jahrhunderts auftreten und den Übergang von der Handschrift zum Druck erlebt haben. Auch wenn, wie erwähnt, die Details der Abhängigkeitsverhältnisse zwischen der den Persenober-Roman enthaltenden Handschrift (Cod. Holm. K 47) und den frühen PersenoberDrucken nicht ganz geklärt sind, so stellt das Manuskript in jedem Fall ein wichtiges Bindeglied zwischen der Handschriftenkultur und dem beginnenden Buchdruck in Dänemark dar. Ganz offensichtlich versprachen sich Drucker wie Gotfred af Ghemen und Laurentz Benedicht von den ursprünglich aus dem französischen Mittelalter stammenden Versromanen Flores oc Blantzeflor und Persenober einen entsprechenden Absatz bei ihrer Käuferschaft - neben anderen, ebenfalls mehrfach aufgelegten Frühromanen und Erzähltexten wie Sigismunda, Griseldis (beide Erstdruck 1528), Marcolfus (1540), Uglspil (Eulenspiegel, vor 1571), Fortunatus (1575), Magelona (1583) und anderen. ${ }^{28}$

26 Glauser, Skandinavische Literaturgeschichte (Anm. 8), S. 56. [Vgl. für die Entwicklung von der Handschrift zum Druck in den anderen Sprachgebieten die Beiträge von BertelsmeierKierst (Seite 36), Besamusca und Willaert (Seite 68) und Sánchez-Martí (Seite 144) in diesem Band.]

27 Die beiden Flores-Drucke aus dem Jahre 1504 sind nur fragmentarisch erhalten (beide enthalten denselben Textausschnitt, nämlich sechs Blätter, Bl. 3, 4 und 5, sowie jeweils Teile von Bl. 1, 6 und 7, beide mit demselben Holzschnitt auf Bl. $1^{\mathrm{r}}$ ) und befinden sich im Besitz der Uppsala Universitetsbibliotek (Sign. Danica vet. 26, $8^{\circ}$ und Danica vet. 26a, $8^{\circ}$ ). Der erste vollständige Druck Flores oc Blantzeflor 1509 gehört zur Sammlung der Königlichen Bibliothek Kopenhagen, Sign. LN 67, $8^{\text {to }}$ (digitalisiert auf Early European Books).

28 Vgl. Glauser, Skandinavische Literaturgeschichte (Anm. 8), S. 59-60. 


\section{Transformationen: Rewriting als Modell für die Adaption und Bearbeitung von Erzähltexten in der dänischen Frühdruckzeit}

Preist der Druck von 1572 gleich im Titel seinen potentiellen Leserinnen und Lesern die Erzählung als „lystig oc skøn Historie““29 an, welche „nu nylige offuerseet oc Corrigerit“ ${ }^{30}$ sein soll, so rekurriert er hier auf eine für diese Textsorte gebräuchliche und auch im deutschen Sprachraum verbreitete Rhetorik und Textproduktionspraxis. ${ }^{31}$ Die dänische Persenober-Erzählung ist ein gutes Beispiel dafür, wie ein Erzähltext im Prozess eines produktiven und kreativen rewriting mehrfach bearbeitet, adaptiert und nachgedruckt wurde, wobei der (meist anonyme) Übersetzer durchaus in den Text eingreifen, Kürzungen vornehmen und auch ganze Passagen abändern und ,korrigieren' konnte - insbesondere vor dem Hintergrund, dass es sich um einen volkssprachlichen Erzähltext handelt. ${ }^{32}$ Im Folgenden soll rewriting oder Retextualisierung, wie Joachim Bumke für die zahlreichen Bearbeitungs-, Übersetzungs- und Adaptionsprozesse mittelalterlicher Texte vorgeschlagen hat, ${ }^{33}$ auch als eine Form von (durchaus positiver) ,Manipulation' verstanden werden, wie es der belgische Übersetzungstheoretiker André Lefevere formuliert hat:

Translation is, of course, a rewriting of an original text. All rewritings, whatever their intention, reflect a certain ideology and a poetics and as such manipulate literature to function in a given society in a given way. Rewriting is manipulation, undertaken in the service of power, and in its positive aspect can help in the evolution of a literature and a society. Rewritings can introduce new concepts, new genres, new devices and the history of translation is the history also of literary innovation, of the shaping power of one culture upon another. ${ }^{34}$

29 „unterhaltsame und schöne Historie“ (Persenober 1572, Bl. A1 ${ }^{\mathrm{r}}$ ).

30 ,jetzt unlängst durchgesehen und korrigiert“ (Persenober 1572, Bl. A1 ${ }^{\mathrm{r}}$ ).

31 Vgl. Richter, Transmissionsgeschichten (Anm. 16), S. 17 und ausführlich in: Lauritz Nielsen, Dansk bibliografi: med saerligt hensyn til dansk bogtrykkerkunsts historie. 3 Bde. København 1919-1935.

32 Für die mittelalterliche Übersetzungspraxis vgl. etwa Rikhardsdottir (vgl. Anm. 3), S. 5 und zu volkssprachlicher Literatur ebda., S. 116: „The notion of textual fidelity was in fact foreign to a mindset that viewed vernacular texts and stories not as singular and fixed entities, but rather as collective material to draw on in the creative process."

$33 \mathrm{Vgl}$. Joachim Bumke und Ursula Peters (Hgg.), Retextualisierung in der mittelalterlichen Literatur. Sonderheft Zeitschrift für Deutsche Philologie 124 (2005), hier insb. S. 1-5.

34 André Lefevere, Translation, Rewriting and the Manipulation of Literary Fame, London, New York 1992, S. vii. 
Der dänische Persenober-Druck von 1572 mit seinen unterschiedlichen ,Vorgänger-Texten“ - nämlich dem mittelalterlichen französischen PartonopeuRoman, der altnorwegischen Partalopa saga, dem Ms. Cod. Holm. K 47, dem Erstdruck von 1560 - stellt mithin ebenfalls ein rewriting dar. Erzählungen wie Persenober oc Constantianobis dokumentieren die komplexe Transmission und damit auch Transformation höfischer Texte mit einer langen kontinentaleuropäischen Tradition, sie machen die mouvance des Textes, seine Unfestigkeit und seinen Reichtum an variance im Laufe seiner Manuskript- und Drucktransmission deutlich. ${ }^{35}$ In den unterschiedlichen Bearbeitungs- und Übersetzungsstufen zeigt sich nämlich eine Produktivität und Kreativität, die die Rezeption und auch die Kontinuität höfischer Literatur in Skandinavien veranschaulicht.

Im Folgenden sollen drei Beispiele für solche produktiven Äußerungsformen von rewriting am dänischen Persenober-Druck von 1572 gezeigt werden: erstens Auslassungen resp. Ellipsen, die eine Akzentverschiebung in der Erzählung evozieren, zweitens eine Nachschrift an den Leser sowie drittens eine Textstelle, deren Bearbeitung durch den dänischen Übersetzer eine moralisierende Steuerung der zeitgenössischen Rezeption und eine Besonderheit in der dänischen Tradierung darstellt. An diesen Beispielen soll verdeutlicht werden, auf welche Weise der Text im Umfeld der Frühdruckzeit in Dänemark für sein Publikum adaptiert wurde. Ich werde mich also primär auf diese Druckversion beziehen und je nachdem auch die Manuskriptfassung Codex Holm. K 47, die Partalopa saga und die französische Fassung vergleichsweise heranziehen. ${ }^{36}$ Der komplexen gesamtskandinavischen Partonopeu-Transmission vermag dieser kurze Beitrag freilich nicht Rechnung zu tragen, doch soll immerhin ein erster Einblick in das dänische Material gewonnen werden.

35 Mit mouvance wird auf die Begriffsbildung bei Paul Zumthor in seinem Essai de poétique médiévale von 1972 rekurriert, vgl. Paul Zumthor, Toward a Medieval Poetics. Übers. v. Philip Bennett. Minneapolis 1992, vgl. insb. S. 40-76; variance nach Bernard Cerquiglini, Éloge de la variante: historie critique de la philologie. Paris 1989 und Unfestigkeit geprägt durch Joachim Bumke, zuerst in Die vier Fassungen der 'Nibelungenklage'. Untersuchungen zur Überlieferungsgeschichte und Textkritik der höfischen Epik im 13. Jahrhundert. Berlin, New York 1996, vgl. insb. S. 53-60.

36 Auch wenn die französische Fassung zur Y-Textgruppe gehören, ist es in der Forschung unumstritten, dass die altnorwegische Saga auf einer französischen Vorlage beruht. Vgl. Partalopa saga (vgl. Anm. 20), S. XIII. 


\section{Rewriting I: Abweichungen, Ellipsen}

Allein über die zahlreichen Unterschiede zwischen den skandinavischen Textversionen (d.h. der Partalopa saga und den dänischen Textzeugnissen der frühen Neuzeit) und dem französischen Partonopeu ließe sich vor dem Hintergrund der Translation französischer romances nach Skandinavien im Mittelalter sehr viel sagen. ${ }^{37}$ So sind etwa viele der ausführlichen Turnier- und Kampfschilderungen des französischen Textes in der Saga wie auch im Manuskript Cod. Holm. K 47 und im Benedicht-Druck 1572 ausgelassen worden, ebenso retardierende Erzählmomente, außerdem die Differenz zwischen Heidentum und Christentum, die langen Dialoge und die psychologisierende Darstellung der Figuren, insbesondere in der Liebesgeschichte zwischen Partonopeu (resp. Partalopi/ Persenober) und Melior (resp. Marmoria/ Constantianobis). ${ }^{38}$

In diesem überblicksartigen Beitrag, der nur einige exemplarische Textbeispiele auswählen und daran die Charakteristika der dänischen Transmissionsgeschichte dieses Romans zeigen kann, sollen solche rewriting-Prozesse, auch und gerade mit ihren Auslassungen oder Abweichungen als Repräsentationen textueller Dynamik, Unfestigkeit und mouvance verstanden werden.

Zunächst einmal fällt auf, dass etwa der gesamte Prolog und die beim Trojanischen Krieg beginnende Genealogie (Pré-histoire) des französischen Textes schon in der Partalopa saga und auch im dänischen Persenober 1572 ausgelassen sind. Dadurch entfällt die Rhetorik des Erzählers, wie er im französischen Partonopeu agiert, in diesem einleitenden Teil ${ }^{39}$; geblieben ist im dänischen Druck an dieser Stelle die nur sehr kurze einleitende Formel des anonymen Ich-Erzählers: „It Euentyr vil ieg sige fra/ I huo som der vil lyde paa/ Aff en mectig Konnig rig/ Mand finder icke nu mange slig.“ (Bl. A2 $).{ }^{40}$ Am Anfang der Erzählung in Laurentz Benedichts Druck steht (aufgrund der Zugehörigkeit zur Y-Textgruppe) denn auch nicht die Jagd in den Wäldern der Ardennen, sondern die Schilderung von Prinzessin Constantianobis' Kindheit und Jugend, von ihrer außerordentlichen Klugheit und Schönheit (Bl. $\mathrm{A} 2^{\mathrm{r}}$ ), dann folgt der Tod von ihres Vaters (Bl.

37 Vgl. Rikhardsdottirs (vgl. Anm. 3) ausführliche Analyse auf S. 113-163. Sie vergleicht beispielsweise den altnorwegischen Sagatext mit den beiden mittelenglischen Versionen sowie mit der französischen Textfassung (ebda., S. 152-163).

$38 \mathrm{Vgl}$. zu diesen Auslassungen (für die Sagafassung) Lise Præstgaard Andersens Kommentar in Partalopa saga (vgl. Anm. 20), S. XXIII-XXV.

39 Vgl. Le Roman (vgl. Anm. 21), S. 70-94 (VV. 1-498).

40 „Ein Abenteuer will ich erzählen, allen, die zuhören mögen, von einem mächtigen und reichen König; seinesgleichen findet man heutzutage nicht mehr viele.“ (Diese und folgende Zitate beziehen sich auf die erwähnte Ausgabe von Laurentz Benedicht, Kopenhagen 1572.) 
$\mathrm{A} 2^{\mathrm{v}}-\mathrm{A} 3^{\mathrm{r}}$ ) und die Aufforderung des königlichen Rates an Constantianobis, einen Ehegatten $\mathrm{zu}$ wählen (Bl. $\left.\mathrm{A} 3^{\mathrm{r}}\right)$. Constantianobis lässt hierauf zwölf Ritter $\mathrm{zu}$ sich rufen und sendet sie aus, um einen geeigneten Kandidaten $\mathrm{zu}$ suchen (Bl. $\mathrm{A} 3^{\mathrm{r}}{ }^{\mathrm{r}}$ $A 3^{v}$ ). Der zwölfte Ritter überreicht der Prinzessin bei seiner Rückkehr einen Brief mit der Beschreibung eines jungen Mannes, der ihr schließlich am meisten zusagt - es ist Persenober, der Neffe des französischen Königs (vgl. Bl. A4 ${ }^{\mathrm{r}}$ ). Constantianobis gelangt mittels ihrer zauberischen Kräfte nach Frankreich und überzeugt sich selbst - unsichtbar für die anderen - am Hofe des französischen Königs von der Wahrheit der Beschreibung des Prinzen, er gefällt ihr und sie würde ihn wohl gern als Ehemann auswählen. In dieser ganzen ersten Passage stimmt die Druckfassung mit der Version in der Handschrift Cod. Holm. K 47 fast wortwörtlich überein. ${ }^{41}$

In der Partalopa saga ist der Anfang ganz ähnlich, doch wird der Akzent anders gesetzt: Hier dominiert das Motiv der meykongr (maiden-king) aus der isländischen Erzähltradition - Prinzessin Marmoria, der ihre Berater ebenfalls zur Heirat raten, damit das Reich einen Souverän bekommt, will ihre Autorität und Unabhängigkeit als Herrscherin nicht aufgeben, heiraten würde sie nur einen in Ritterlichkeit und Klugheit ihr würdigen Mann, den sie aber nicht unter den Prinzen ihres Landes finden kann. ${ }^{42}$ Als sie mittels Zauberei nach Frankreich gelangt, weil sie von den Tugenden des französischen Königssohns gehört hat, und diesen, nämlich Partalopi, dann auch selbst zu sehen bekommt, gefällt er ihr durchaus. Jedoch will sie ihre Unabhängigkeit als Herrscherin nicht aufgeben und beschließt daher, Partalopi zwar für sich zu gewinnen, aber:

ok kom henni bat jhvg at hon matti slikann mann eignazt bo at eigi vissi hennar radgiafar treystir hon ok svo vel sinvm klerkdomi at | hon matti hann lata fara hvert er hon villdi en pvi gerdi hon petta at hon villdi ongvann mann lata vera sier rikara ef hon mætti rada ok sa hon pat sem var at sa mvndi keisari verda yfir allri Grecia er hennar feingi ok sa mvndi rikari verda en hon ok potti henni pat mikil minkan at heita sidan keis<ar>ina par er advr het hon meykongvr yfir P(artalopa) ok morgvm oqdrvm hǫfdingivm. Sidan for hon aptvr til Mikla gardz ok gerdi sier pat ihvg at hon skylldi leyniliga med pessu mali fara ok fa hann po allt at einv [...] ok let svo fyrir vinvm sinvm at hon villdi ongvm manni giptazt peim er par vissi hon deili. ${ }^{43}$

(Es kam ihr in den Sinn, einen solchen Mann zu bekommen, auch wenn ihre Berater nichts [davon] wussten. Und sie vertraute so sehr auf ihre Klugheit [gemeint sind ihre

41 Vgl. https://tekstnet.dk/persenober-og-konstantianobis/2.

42 Vgl. Partalopa saga (vgl. Anm. 20), S. 8-9 und S. 2-3 (Text) bzw. S. 130-131 (engl. Übersetzung); dazu auch Kalinke, 'Scribe, Redactor, Author' (Anm. 20), S. 187-189.

43 Vgl. Partalopa saga (vgl. Anm. 20), S. 7-9. 
zauberischen Künste], dass sie ihn überallhin gehen lassen konnte, wohin sie nur wollte. Und dies tat sie, weil sie keinen Mann mächtiger als sie selbst sein lassen wollte, wenn es nach ihr ging. Und für sie war es so, dass derjenige, welcher sie heiratete, Kaiser über ganz Griechenland werden würde und dieser wäre dann mächtiger als sie. Dies schien für sie eine große Herabsetzung ihrer Stellung zu bedeuten, dass sie dann Kaiserin heißen würde und nicht wie zuvor meykongr über Partalopi und alle anderen Fürsten. Daraufhin reiste sie zurück nach Konstantinopel und beschloss, dass sie dies heimlich regeln und ihn [Partalopi] gleichwohl bekommen würde. Sie [...] gab vor ihren Freunden vor, niemanden der Männer zu heiraten, die ihr bekannt waren.) $)^{44}$

Sif Rikhardsdottir verweist an dieser Stelle auf die Bedeutung des maiden-kingMotivs in der isländischen Literatur und auf den markanten Unterschied zwischen dem Sagatext und den französischen und englischen Fassungen, wo die Hochzeit zwischen Melior und Partonopeu nur aufgrund der Jugend des Protagonisten aufgeschoben wird. ${ }^{45}$ In der folgenden Episode wird daraufhin erzählt, wie Partalopi sich während eines Jagdausflugs verirrt und schließlich (implizit durch Marmorias Zauberkräfte) nach Konstantinopel und in ihr Schloss gelangt. Auch in den dänischen Textfassungen (Manuskript Cod. Holm. K 47 und Druck von 1572) folgen der Jagdausflug und die Reise Persenobers zum Feenschloss, welche als von Constantianobis' magischen Kräften gelenkt erscheinen. ${ }^{46}$ Das Motiv der unabhängigen maiden-king-Herrscherin ist in den frühneuzeitlichen dänischen Versionen aber nicht mehr präsent und scheint somit ein Spezifikum der spätmittelalterlichen Partalopa saga in ihrem kulturell-literaturhistorischen Kontext zu sein.

44 Dt. Übersetzung von mir, AKR. Englische Übersetzung in der Ausgabe der Partalopa saga, vgl. Partalopa saga (vgl. Anm. 20), S. 133-134: „It entered her mind that she could get such a man, even though her counselors did not know [about it]. She also trusted so well in her learning that she could cause him to go where ever she wished. She did this, because she wanted to let no man be more powerful than herself, if she might have her way. She perceived that - as it was - that that one would become emperor of all Greece who married her, and that one would be more powerful than she. That seemed to her a great abasement to be called afterwards empress where before she was called maiden-king over Partalopi and many other chieftains. After that she went back to Constantinople and took it into her head that she should secretly deal with this matter and get him nevertheless. She [...] pretended thus to her friends that she did not wish to marry any man of those she knew.“

45 Vgl. Rikhardsdottir (vgl. Anm. 3), S. 121-123.

46 Im französischen Text geht die erste, sehr ausführlich geschilderte erotische Begegnung zwischen den beiden Protagonisten der Aussicht auf die Eheschließung voraus. Vgl. Le Roman (vgl. Anm. 21), VV. 1401-1564 und Eley (vgl. Anm. 3), S. 219, zur Jugend des Helden vgl. hier insb. S. 19-32. 


\section{Rewriting II: Zusätze im dänischen Druck von 1572}

Wie dynamisch der Text in seinem Transmissionsprozess bleibt, zeigen zwei besondere Erweiterungen, die der Druck bei Laurentz Benedicht 1572 gegenüber der Handschrift Cod. Holm. K 47 besitzt, auf die bereits Brandt in seiner Ausgabe im 19. Jahrhundert kurz hingewiesen hat ${ }^{47}$ und die im Folgenden präsentiert werden sollen.

\subsection{Ein erweiterter Schluss}

Zunächst einmal hängt der Druck aus Laurentz Benedichts Offizin 1572 einen erweiterten Schluss an das in der Handschrift erzählte eigentliche Ende der Historie an, welche dort mit der Hochzeit von Persenober und Constantianobis, deren Tod und der Datierung des Textes schließt. So heißt es im Manuskript Cod. Holm. K 47:

giorde thieris brøllop i same stad/ the adhe och drwke och waræ glad/ sidhen bleff then edlæ mand/ konningh och herræ ower thet land/ the ende thieris liiff och finge roo/ och mon medh gud i hemerigh boo/ [196r] thenne bogh worte dikt i rym/ aar effter gusz fødsels tim/ thet wil jech seye obenbaræ/ twsind oc iiii hwndret aar/ firæ sindis tywe paa thet fierde amen

(Persenober, VV. 1580-1590, Bl. 195 $\left.5^{\mathrm{v}}-196^{\mathrm{r}}\right)^{48}$

(Sie hielten ihre Hochzeit in derselben Stadt, aßen und tranken und waren fröhlich. Danach wurde der edle Mann [Persenober] König und Herr über das Land. Sie beschlossen ihr Leben und fanden ihren Frieden; mögen sie nun mit Gott im himmlischen Reiche wohnen. Dieses Buch wurde in Verse gesetzt im Jahre - das will ich offenbaren - eintausendvierhundertvierundachtzig Jahre nach der Geburt des Herrn, Amen.)

Hier fügt der Druck nach der Krönung Persenobers noch zehn neue Zeilen ein (vgl. Bl. $\mathrm{D} 7^{\mathrm{r}}-\mathrm{D} 7^{\mathrm{v}}$ ) und berichtet in diesem eingeschobenen Passus von der Aufteilung des Reiches unter den drei Söhnen des Herrscherpaares (welche in der Handschrift gar nicht vorkommen), des Weiteren von der Bekehrung des

47 Carl Joakim Brandt, Romantisk Digtning fra Middelalderen. Bd. II. København 1870, S. 378-382; und Brandt, Romantisk Digtning III (Anm. 25), S. 334-335.

48 Lemmatisierter Text zitiert nach der Online-Edition: https://tekstnet.dk/persenober-og-kon stantianobis $/ 10$ 
heidnischen Königs, um dann ebenfalls in einem formelhaften Gebet des anonymen Ich-Erzählers, in das Zuhörer und Leser eingeschlossen sind, zu enden:

$\mathrm{Nu}$ befaler ieg alle mand/ Gud Fader Søn og Hellig Aand/ Gud vnde oss alle den euige ro/ At wi maa bliffue vdi en stadig tro/ Paa vor siste ende/ Naar wi skulle fare vdaff dette elende/ Nu er denne Bog til ende/ Gud oss sin Naade sende. Amen./ Ende paa denne Historie.

(Persenober 1572, Bl. D7 ${ }^{\mathrm{r}}-\mathrm{D} 7^{\mathrm{V}}$ )

(Nun empfehle ich jedermann Gottvater, Sohn und dem Heiligem Geist. Möge Gott uns allen die ewige Ruhe schenken, auf dass wir in einem festen Glauben verbleiben an unserem Lebensende, wenn wir dieses irdische Elend verlassen. Nun ist dieses Buch zu Ende. Gott möge uns seine Gnade schenken, Amen. Ende dieser Historie.)

Das Motiv von der Aufteilung des Königreiches unter die Kinder findet sich übrigens auch am Ende des in derselben Handschrift Cod. Holm. K 47 enthaltenden Versromans von Flores oc Blantzeflor. Dort gibt es eine interessante Varianz: In der Manuskriptversion wird von der Aufteilung der Herrschaft unter die zwei Söhne und der einzigen Tochter des Paares erzählt, mit welcher implizit Berthe, die Mutter Karls des Großen aus der französischen Charlemagne-Texttradition gemeint ist, Flores und Blantzeflor somit als Groß- und Stammeltern Karls des Großen figurieren. In der altnorwegischen Flóres saga ok Blankiflúr (entstanden im 13. Jahrhundert, Textzeugnisse jedoch erst aus dem 14. Jahrhundert erhalten) sowie im altschwedischen Flores (1312) und interessanterweise dann (erst wieder) in der Drucküberlieferung der dänischen Historie von Flores oc Blantzeflor ab 1509 sind es dagegen drei Söhne, keine Tochter. ${ }^{49}$ Es ist bemerkenswert, dass das (genealogische) Erzählen von der Kontinuität der Herrschaft bei Flores oc Blantzeflor in der Manuskriptversion stärker betont wird, im Persenober dagegen (nur) in der späteren Druckfassung.

\subsection{Die Nachschrift „Til Læseren“}

Im Anschluss an dieses „Ende der Historie“ folgt als zweite Neuerung des Drucks gegenüber dem Manuskript noch die Nachschrift „Til Læseren“ (Bl. D7-D8 ${ }^{\mathrm{r}}$ ) und eine Vignette des Druckers. Diese Nachschrift ist ein neues paratextuelles Element, das erst mit den Druckfassungen in die Transmission der dänischen

49 Vgl. hierzu Anna Katharina Richter, 'La transmission de Floire et Blancheflor au Danemark $\left(\mathrm{XV}^{\mathrm{e}}-\mathrm{XVII}{ }^{\mathrm{e}}\right.$ siecles)', mit weiterführenden Literaturangaben, in: L'Expérience des frontières et les littératures de l'Europe médiévale. Hg. v. Sofia Lodén und Vanessa Obry. Paris 2019 (Colloques, Congrès et Confèrences - Le Moyen Âge, 26, 1 vol.) (in Vorbereitung). 
Historie hinzugekommen ist. ${ }^{50}$ Hier lassen sich vier Aspekte ausmachen, die buch- und überlieferungshistorisch interessant sind: erstens die Datierung der Erzählung, die fast wortgetreu aus der Vorlage übernommen wird: „Denne Historie vaar sat paa rim/ Aar efter Guds fødzels time/ Det vi lieg sige obenbar/ Tusind firehundrit aar/ Firesindstiue paa det fierde/ Det skal vide baade lege oc lærde.“ (Bl. D7 ${ }^{\mathrm{v}} .^{51}$ Damit wird indirekt auf die Handschrift Cod. Holm. K 47 (oder ggf. eine andere, evtl. nicht erhaltene zeitnahe Handschrift) verwiesen und wird nicht nur - wie schon oben vermerkt - im Textkorpus selbst, sondern auch in der Nachschrift das Jahr 1484 als Genese der dänischen Textfassung angegeben. Zweitens nennt die Nachschrift auch einen namentlichen Übersetzer, einen gewissen Hendrick Christensen aus dem norwegischen Bergen, der den Text aus dem Deutschen ins Dänische übersetzt haben soll: „Den som Bogen aff tyske oc til danske vende/ Er født i Bergen iblant de haarde Steen/ [...] Hendrick Christensen er hans naffn“ $\left(B 1 . D 7^{\mathrm{v}}-\mathrm{D} 8^{\mathrm{r}}\right)^{52}$ und es wird drittens auf die Existenz der früheren Ausgabe von 1560 verwiesen. Viertens wird schließlich auf den konkreten Bearbeitungsprozess der vorliegenden Ausgabe aufmerksam gemacht und zugleich auch die für die frühen Romane sehr übliche, rezeptionslenkende wie auch ökonomisch relevante (indem der Text einer bestimmten Textsorte zugordnet, das Leserinteresse und damit auch die Kauf-

50 Der spätere Druck von 1700 übernimmt die Nachschrift aus dem Druck von 1572, stellt sie der Erzählung aber nunmehr als Vorwort voran. Ob es bereits im (verlorenen) Druck von 1560 auch eine solche Nachschrift gab, lässt sich nicht rekonstruieren; der Druck vom Ende des 16. Jahrhunderts ist unvollständig (s.o., Anm. 7), Drucke des 17. Jahrhunderts sind ebenfalls nicht erhalten. Vgl. dazu auch Brandt, Romantisk Digtning II (Anm. 25), S. 381-382 und DF VI, S. 408-416.

51 „Dieses Buch wurde in Verse gesetzt im Jahre - das will ich kundtun - tausendvierhundertvierundachtzig nach der Geburt des Herrn. Dies sollen sowohl Laien als auch gelehrte Leute wissen.“

52 „Der das Buch aus dem Deutschen ins Dänische übersetzt hat, ist geboren in Bergen zwischen den harten Steinen [wohl eine Anspielung auf die felsige Küstenlandschaft vor Bergen?], Hendrick Christensen ist sein Name.“ - Bereits Brandt zweifelte jedoch an der Identität des Übersetzers Hendrick Christensen, die Herausgeber von Danske folkebøger ziehen einen „bogfører“ (Buchführer) Henrik aus Bergen († 1560) als möglichen Übersetzer und Bearbeiter in Erwägung, vgl. dazu DF VI, S. LXIII. Dass nun ein (hoch- oder nieder-)deutscher Partonopeu als Übersetzungsvorlage für den dänischen Druck angegeben wird, macht die Frage nach den Vorlagen angesichts der unterschiedlichen beiden Haupt-Textgruppen nicht einfacher. Da die dänische Fassung mit der norwegisch-isländischen große Gemeinsamkeiten aufweist und es sich hier zudem um eine Nachschrift handelt, erscheint dieser Verweis wenig überzeugend. Er bedarf jedenfalls zusätzlicher Klärung, die noch aussteht und an dieser Stelle leider nicht beantwortet werden kann. 
lust geweckt wird) Zuschreibung von „nutz und kurtzweyl“ ausgesprochen gewissermaßen ein ,Label', das einen hohen Wiedererkennungseffekt für das zeitgenössische Lesepublikum besaß ${ }^{53}$ :

Der mand screff M.D. hundrit Aar/ Effter Christi Fødzel alt obenbar/ Oc der til lige Trysinds tiue/ Ieg vil de ticke liuffe/ Da bleff Bogen først tryct paa ny/ Vdi den Kongelige Stad Kiøbenhaffn/ mangen til lærdom/ nytte oc gaffn/ Nu nylig offuerseet oc forbedrit/ Oc mange steder Corrigerit.

(Persenober 1572, Bl. D7 ${ }^{\mathrm{v}}-\mathrm{D} 8^{\mathrm{r}}$ )

(Da man schrieb 1500 Jahre nach Christi Geburt und dazu noch sechzig Jahre, ich will nicht lügen, da wurde das Buch erstmals gedruckt in der königlichen Stadt Kopenhagen. Vielen zur Belehrung, zum Nutzen und zur Unterhaltung. Nun unlängst durchgesehen und verbessert und vielerorts korrigiert.)

Mit dem formelhaften „mangen til lærdom/ nytte oc gaffn“ korrespondiert auch der eingangs präsentierte Titel der Erzählung, ,[e]n lystig oc skøn Historie [...] Lystig at høre oc læse“ (Bl. A1 $\left.{ }^{\mathrm{r}}\right)$, welcher in dieser oder ähnlicher Formulierung für die frühneuzeitlichen dänischen und schwedischen Historien sehr häufig auftritt und von den gängigen deutschen Historienbuch-Titeln wie etwa „Eine schöne und vergnügliche Historie“ oder ähnlichen Formulierungen übernommen ist. ${ }^{54}$

\section{Rewriting III: Besonderheiten der frühneuzeitlichen dänischen Tradierung in Handschrift und Druck am Beispiel der nächtlichen Begegnung zwischen Persenober und Constantianobis}

Abschließend sei darauf hingewiesen, dass die dänische Überlieferung im Vergleich zur Partalopa saga einige korrigierte Passagen enthält. Eine davon findet

53 Zum Aspekt von Didaxe und Unterhaltung oder „nutz und kurtzweyl“ der Prosahistorien vgl. die für den deutschen Sprachraum einschlägige Literatur, grundlegend Jan-Dirk Müller, 'Volksbuch/Prosaroman im 15./16. Jahrhundert. Perspektiven der Forschung'. In: Internationales Archiv für Sozialgeschichte der Literatur 1 (1985), Sonderheft (Forschungsreferate), S. 1-128, hier S. 84.

54 Vgl. Richter, 'La transmission' (Anm. 49). 
sich sowohl im Manuskript Codex Holm. K 47 als auch im Benedicht-Druck und stellt m.E. ein interessantes Beispiel für einen textuellen Eingriff im Sinne der Lefevere'schen manipulation dar. Möglicherweise ist sie sogar ein einzigartiges, spezifisches Charakteristikum der dänischen Transmission des PartonopeuRomans. Es geht um die erste Begegnung zwischen Persenober und Constantianobis, welche nachts im Schloss der Prinzessin stattfindet, wo der Held von unsichtbaren Dienern bedient und wie von Feenhand köstliche Speisen serviert und schließlich zu einem mit zahllosen Edelsteinen geschmückten königlichen Bett geleitet wird, wo er sich schlafen legt. Schon bald bemerkt er jedoch, dass er dort nicht allein ist. Im französischen Roman wird an dieser Stelle der darauffolgende „dialogue avec l'inconnue“ ausführlich beschrieben, ebenso die anschließende erotische Begegnung zwischen Partonopeu und „la dame“, erst danach gibt nämlich Melior ihre Identität preis und es folgt das Tabu-/ Sichtversprechen. ${ }^{55}$

In der Partalopa saga entspinnt sich hier nur ein relativ kurzes, aber interessantes Gespräch zwischen Partalopi und der ihm noch unbekannten Frau; es heißt dann abschließend:

Nv skempta pav sier ba nott eptir pvi sem peim likadi ok sofnvdv sidan jógrv fadmlage ok godv ${ }^{56}$

(Nun vergnügten sie sich in dieser Nacht ganz so, wie es ihnen gefiel und danach schliefen sie in einer schönen und guten Umarmung ein. $)^{57}$

Der Sagatext nimmt hierin zwar sehr kurz, aber doch deutlich (der Rest mag der Phantasie des Lesers/Zuhörers überlassen worden sein) den Topos der Liebesnacht auf - wobei es in dem dieser Textstelle unmittelbar vorausgehenden Passus bezüglich der Macht- und Autonomieverhältnisse zwischen den beiden Protagonisten markante Unterschiede zur Darstellung im französischen Partonopeu-Roman gibt, wie Rikhardsdottir bemerkt. ${ }^{58}$ Doch nochmals ganz anders ist der Wortlaut in der spätmittelalterlich-frühneuzeitlichen dänischen Tradierung und zwar in fast wörtlicher Übereinstimmung zwischen der Handschrift Cod. Holm. K 47 und dem Druck von 1572. Die delikate Textstelle ist hier

55 Vgl. Le Roman (vgl. Anm. 21), VV. 1105-1570.

56 Partalopa saga (vgl. Anm. 20), S. 33, Kap. 4, Z. 133-135 (nach der Handschrift AM $5334^{\text {to }}$ ).

57 Engl. Übersetzung von Foster W. Blaisdell nach der Handschrift AM $5334^{\text {to }}$ : „Now they entertained each other that night according to that which pleased them and fell asleep afterward in a lovely and good embrace.“ (Partalopa saga (vgl. Anm. 20), S. 148).

58 Vgl. Rikhardsdottir (vgl. Anm. 3), S. 125-126. 
wesentlich gekürzt und die eigentliche Liebesnacht sogar gänzlich weggelassen, als ob der Text eine Zensur durchlaufen hätte: Persenober ist zunächst allein, dann betritt Constantianobis das Zimmer und setzt sich zu Persenober ans Bett, woraufhin sich dieser zur Wand dreht und Christus um Schutz bittet, droht ihm doch als Eindringling in ihr Schloss das Todesurteil. In der folgenden Rede, die die Prinzessin an Persenober richtet, eröffnet sie ihm jedoch die Aussicht auf die gemeinsame Ehe (nach einer halbjährigen Wartezeit), unter der Bedingung, dass er das Tabugebot einhalten müsse:

Det siger ieg dig sandelig/ At ieg vil dig til herre haffue/ Oc aldrig andre i min dage/ [...] Huer nat skalt du ligge hoss mig/ Dog maa de ticke andit være/ End du skalt ligge hoss mig met ære/ Oc ingen whøffuiskhed mig at byde/ Om du vilt mit raad lyde/ Det siger ieg dig sandelig/ Ieg vil om natten tale met dig/ Huad oss kand baade være til glæde/ [...] Met megen glæde oc ære/ Oc da skal vort Bryllup være. (Persenober 1572, Bl. A8 $\left.{ }^{\mathrm{r}}-\mathrm{A} 8^{\mathrm{V}}\right)^{59}$

(Dies sage ich dir wahrlich: dass ich dich und keinen anderen zu meinem Herrn haben will [...] Jede Nacht sollst du bei mir liegen, doch soll es nicht anders sein als mit Ehre und du darfst mir gegenüber kein maßloses Benehmen zeigen. Wenn du meinem Rat folgst - das sage ich dir wahrhaftig - dann will ich mich des Nachts mit dir unterhalten, was uns beide erfreuen kann. [...] Mit Freude und Ehre soll dann unsere Hochzeit stattfinden.)

Auffallend ist die deutliche Betonung des anständigen, ,richtigen“ Benehmens, der Vokabel „Ehre“ und der dagegengesetzte Gebrauch des Ausdrucks „whøffuiskhed“ als dessen offensichtliches Gegenteil: Hier weichen der dänische Versroman wie auch die Druckfassung 1572 deutlich von der altnorwegischen Saga ab und zeigen eine einschneidende Bearbeitung, die eine pikante Passage wie diese bewusst auslässt. Nur ex negativo, in der Negierung (,whøffuiskhed“) beziehungsweise bloß in vorsichtiger, andeutender Rede (,dann will ich mich des Nachts mit dir unterhalten, was uns beide erfreuen kann“) wird skizziert, was narrativ noch möglich wäre. (Von nächtlichem „unterhalten“ war im Sagatext allerdings nicht die Rede.)

59 Vgl. die entsprechende Formulierung in der Handschrift Cod. Holm. K 47 (Bl. 174v, VV. 336-371): „tha swared hanum then jomfrv righ/ thet seyer jech eder sannelig/ ath jech wil thik til herræ hawæ/ och aldrigh andræ i mynæ dawæ/ [. . . hwær nat skalt thu legge hooss mægh/ dog maa thet jckj anned wæræ/ æn thu skalt leggæ hooss mæg medh æræ/ och jngen vhøwske mæg ath bydhæ/ om thu wilt myt rad lydhæ/ thet seyer jech thik sannelig/ jech wil om natten snakæ medh thik/ [...] medh mygel glede och æræ/ och tha skal wort brøllop weræ." (auf eine Übersetzung wird hier wegen der fast wortgetreuen Übernahme der Passage im oben angeführten Benedicht-Druck verzichtet). 
Das Substantiv „whøffuiskhed“ ist erstmals für das Jahr 1444 im Dänischen belegt und zwar im Kontext geistlicher Ermahnungen. ${ }^{60}$ In Jon Tursens dänisch-lateinischem Wörterbuch aus dem Jahre 1561 steht es als Übersetzung für die lateinischen Begriffe immodestia, intemperantia sowie als „whøffuiskhed i seder og facter“ (maßloses Benehmen in Sitten und Verhalten) sogar für die noch gröbere incivilitas ${ }^{61}$ und gibt damit deutlich eine moralische Wertung menschlichen Benehmens. Hier wird nicht nur ein textueller Eingriff, eine Kürzung und Zensur vorgenommen - die Schilderung der Liebesnacht wird ja komplett ausgelassen -, sondern auch eine semantische Verschiebung und ein im Lefevere'schen Sinne „manipulierendes“ rewriting, das die Persenober-Version in der Handschrift K 47 und den Druck von 1572 im Gegensatz zur Saga deutlich in Richtung moralisierenden Erzählens transportiert. Von dieser Textstelle auf eine erstmals für die Handschrift Cod. Holm. K 47 realisierte, in die Drucktradition übernommene Adaption des Textes im adlig-klösterlichen Milieu und auch auf eine weibliche Kopistin resp. Bearbeiterin der Handschrift insgesamt zu schließen, wie bereits die Herausgeber von Danske folkebøger vermuteten, ${ }^{62}$ ist unter diesem Gesichtspunkt möglich, ${ }^{63}$ aber es ist auch nicht auszuschließen, dass Persenober auch von einem männlichen Kleriker niedergeschrieben worden sein könnte.

Die Retextualisierung bzw. das rewriting an dieser nicht unrelevanten Textstelle gibt der dänischen Persenober-Tradierung (der spätmittelalterlichen

60 Vgl. das digitalisierte Wörterbuch des Altdänischen, Gammeldansk ordbog (https://gammel danskordbog.dk/), das dieses Wort verzeichnet, etwa in spätmittelalterlichen dänischen Klosterregeln sowie in geistlichen Schriften des bedeutenden dänischen Humanisten, Schriftstellers, Reformators und Bibelübersetzers Christiern Pedersen (vor 1480-1554) aus dem Jahre 1515: https://gammeldanskordbog.dk/ordbog?aselect=uh\%C3\%B8viskhet\&query=uh\%C3\%B8ffuisk het (Zugriff am 3.6.2019).

61 Vgl. die von der DSL digitalisierte Edition dänischer Wörterbücher des 16. und frühen 17. Jahrhunderts: http://renaessancesprog.dk/renaissance/ordboger/Tursen1561/142?query_id= 33476 (Zugriff am 9.6.17).

62 Dies auch unter Berücksichtigung der erwähnten Schlussformel des Flores in derselben Handschrift, vgl. DF VI, S. LXII: „Skriveren (Bearbejderen?) er ifølge Slutordene i Floresrimet en Kvinde, vel sagtens en Adelsdame eller Klosterjomfru, og hermed stemmer godt den for den danske Bearbejdelse ejendommelige Fremhæven af Persenobers Afholdenhed overfor Konstantianobis, der sikkert er udsprunget af Anstændighetshensyn og snarest kan antages at skyldes en Kvinde.“ (Der Schreiber (Bearbeiter?) ist den Schlussworten im Flores-Roman zufolge eine Frau, genauer gesagt eine Adlige oder ein Klosterfräulein; und dazu passt auch die für die dänische Bearbeitung eigentümliche Betonung der Abstinenz Persenobers gegenüber Konstantianobis, welche mit Sicherheit auf Gründe der Anständigkeit zurückzuführen ist und am ehesten auf eine weibliche Schreiberin schließen lässt.)

63 Vgl. Glauser, 'Höfisch-ritterliche Epik' (Anm. 8), S. 195. 
Handschrift wie dem Frühdruck) damit eine individuelle Prägung. Durch die Verwendung eines Begriffes wie „whøffuiskhed“ werden Assoziationen zu anderen Textsorten - etwa geistlichen Ermahnungen - geweckt und dem dänischen Publikum ein bestimmter, vertrauter Wertekosmos vermittelt. Hier wird wohl weniger der Aspekt des höfischen Liebesromans in den Mittelpunkt gestellt, sondern eher - neben der „kurtzweyl“ (im Dänischen „gaffn“ in der Formulierung der Nachschrift im Druck von 1572), die die Liebes- und Abenteuergeschichte ihren Lesern und Zuhörern in jedem Fall bietet - auf jeden Fall auch großen Wert auf den (moralischen) Vorbildcharakter der adligen Protagonisten gelegt. Ähnlichkeiten hierzu lassen sich auch im Fall der Transmission von Flores oc Blantzeflor finden, auf die schon hingewiesen wurde. Hier endet die Historie sowohl bereits in der altnordischen Flóres saga ok Blankiflúr, im altschwedischen Flores (1312) wie auch im dänischen Flores-Versroman (Manuskript Codex Holm. K 47) und im ersten vollständig erhaltenen Flores-Druck von 1509 (ebenfalls bei Gotfred af Ghemen in Kopenhagen) mit dem Rückzug des Protagonistenpaares ins jeweilige (Männer- bzw. Frauen-)Kloster. Andererseits wird aber, im Gegensatz zum Persenober, der Liebe, auch der körperlichen Liebe, zwischen Flores und Blantzeflor in derselben Handschrift und im Frühdruck durchaus narrativer Raum gegeben. Auch im Persenober selbst scheint die ausgeführte Passage auf eine Form von ,Zensur` zu deuten, jedoch wird an anderer Stelle wiederum durchaus auch vom nächtlichen Beisammensein von Persenober und Constantianobis erzählt, wenn auch etwas verhalten, aber immerhin, und zwar in der handschriftlichen wie auch in der gedruckten Überlieferung (1572). ${ }^{64}$ Die Thematisierung von Liebe, Keuschheit, Sexualität und die (oftmals auch ambivalente) Rolle moralisierenden Erzählens in den Texten der skandinavischen Frühdruckzeit ist komplex und macht nicht zuletzt gerade deshalb die Historien derart interessant. ${ }^{65}$

64 Vgl. Persenober 1572, Bl. B2 ${ }^{\mathrm{v}}-\mathrm{B} 3^{\mathrm{r}}$, mit dem eingeschobenen kurzen Erzählerkommentar: „Om natten der de laa tilsammen/ De talit met huer anden oc giorde gammen/ [...] Om natten den Jomffru giorde hannem blide./ Ieg vil det lade nu saa være/ Hand haffde der megen ære/ En nat laa hand hoss hendis side/ [...].“ (Nachts lagen sie beieinander, sie sprachen miteinander und hatten ihr Vergnügen [...] Des Nachts erfreute ihn die junge Frau - ich will es dabei belassen - er hatte dabei viel Ehre. Eines Nachts lag er an ihrer Seite [. . .].“ - Und kurz darauf $\left(B l .4^{\mathrm{r}}\right)$ : „Da vaare de baade i hiertet blid/ Hand kyste hendis rosens mund/ Deris kierlighed vaar tusindlund.“ (Da wurden beide von Herzen froh, er küsste ihren Rosenmund, ihre Liebe war tausendfach). Fast wörtlich übereinstimmend auch im Versroman in der Handschrift Cod. Holm. K 47, vgl. https://tekstnet.dk/persenober-og-konstantianobis/4, VV. 485-503 resp. https://tekstnet.dk/persenober-og-konstantianobis/5, VV. 554-556.

65 Diese Thematik bedürfte einer ausführlicheren Darstellung. Hier kann nur auf Texte wie Appolonius af Tyrus oder Euriolus oc Lucretia (Dänisch 1591 resp. 1571/1594) verwiesen werden, die Diskursfelder wie Inzest, Liebe und Ehe behandeln. Vgl. Richter, Transmissionsgeschichten 
Zurück zum „nutz und kurtzweyl“ der Texte: Es es ist sicherlich anzunehmen, dass die Leserschaft der frühen gedruckten Romane in Dänemark ${ }^{66}$ neben dem Unterhaltungswert, den mittelalterliche Texte wie Persenober oc Constantianobis zweifellos boten, in der erzählten fiktionalen Welt also durchaus auch noch Mitte des 16. Jahrhunderts ein Angebot an Identifikationsmodellen gefunden haben im Sinne eines didaktischen „nutz“ (,lærdom oc nytte“ in der Nachschrift) der Erzählung demonstrieren die fiktionalen Helden exemplarisches Handeln und Verhalten.

Es zeigt sich schließlich auch, dass die Retextualisierung eine Brücke zwischen der spätmittelalterlichen Handschrift und dem Benedicht-Druck schlägt und der Übergang zwischen Manuskript- und Druckproduktion für narrative Texte wie Persenober in Dänemark keine eigentliche Grenze darstellt, sondern gerade „[die] Gebundenheit der höfischen Epik in Dänemark zwischen den Epochen späteres Mittelalter und frühe Neuzeit“ und ihre Bedeutung „als transitorische Literatur “67 bemerkenswert ist. Erzähltexte blieben zugleich konstant (in ihrer kontinuierlichen Präsenz auf dem Buchmarkt) als auch dynamisch in ihren rewriting-Prozessen.

\section{Bibliographie}

Brandt, Carl Joakim (Hg.), Romantisk Digtning fra Middelalderen. Bd. II. København 1870. Brandt, Carl Joakim (Hg.), Romantisk Digtning fra Middelalderen. Bd. III. København 1877. Braun, Manuel, 'Historie und Historien'. In: Die Literatur im Übergang vom Mittelalter zur Neuzeit. Hg. v. Werner Röcke und Marina Münkler. München 2004 (Hansers

\footnotetext{
(Anm. 16), S. 282-304 und für die narrative Komplexität der Historien zwischen moralisierendem Erzählen und „vergnüglichem“ Inhalt exemplarisch für den deutschen Kontext Manuel Braun, 'Historie und Historien'. In: Die Literatur im Übergang vom Mittelalter zur Neuzeit. Hg. v. Werner Röcke und Marina Münkler. München 2004 (Hansers Sozialgeschichte der deutschen Literatur vom 16. Jahrhundert bis zur Gegenwart 1), S. 317-361, hier S. 321: „Fast alle Geschichten beanspruchen exemplarische Geltung, indem sie Moral zu vermitteln und Orientierung für die Lebenspraxis zu leisten vorgeben. Die Erzählung löst diesen Anspruch aber häufig nicht ein, ja sie konterkariert ihn immer wieder, weil sich der Stoff gegen die ihm auferlegte Deutung sperrt, weil Erzählmuster Eigensinn entfalten oder weil literarisches Sprechen Überschüsse produziert.“

66 Die komplexe Thematik des Rezipientenkreises in der Frühdruckzeit (vermutlich primär Angehörige des Adels und des aufkommenden städtischen Patriziats) kann hier nur angedeutet werden. Vgl. dazu etwa Glauser, 'Höfisch-ritterliche Epik' (Anm. 8), S. 204 und Richter, Transmissionsgeschichten (Anm. 16), S. 20-21 mit weiterführender Literatur (vgl. dort S. 21, Anm. 71).

67 Glauser, 'Höfisch-ritterliche Epik' (Anm. 8), S. 207.
} 
Sozialgeschichte der deutschen Literatur vom 16. Jahrhundert bis zur Gegenwart 1), S. 317-361.

Bumke, Joachim, Die vier Fassungen der 'Nibelungenklage'. Untersuchungen zur Überlieferungsgeschichte und Textkritik der höfischen Epik im 13. Jahrhundert. Berlin, New York 1996.

Bumke, Joachim und Ursula Peters (Hgg.), Retextualisierung in der mittelalterlichen Literatur. Sonderheft Zeitschrift für Deutsche Philologie 124 (2005).

Cerquiglini, Bernard, Éloge de la variante: historie critique de la philologie. Paris 1989.

Dahlerup, Pil, Dansk litteratur. Middelalder. Bd. II: Verdslig litteratur. København 1998.

Eley, Penny, Partonopeus de Blois. Romance in the Making. Cambridge 2011.

Eufemiavisorna. Bde. I (Flores och Blanzeflor. Hertig Fredrik av Normandie) und II (Ivan Lejonriddaren). Textredigering, kommentarer och ordförklaringar av Henrik Williams. Inledning av Bo Ralph. Stockholm 2018 (Svenska klassiker utgivna av Svenska Akademien).

Ferm, Olle et al. (Hgg.), The Eufemiavisor and Courtly Culture, Time, Texts and Cultural Transfer, Papers from a Symposium in Stockholm 11-13 October 2012. Stockholm, Kungliga Vitterhets Historie och Antikvitets Akademien (KVHAA), 2015 (Konferenser 88).

Glauser, Jürg, 'Höfisch-ritterliche Epik in Dänemark zwischen Spätmittelalter und Frühneuzeit'. In: Festschrift für Oskar Bandle zum 60. Geburtstag am 11. Januar 1986. Hg. v. Hans-Peter Naumann unter Mitwirkung von Magnus von Platen und Stefan Sonderegger. Basel, Frankfurt a.M. 1986 (Beiträge zur nordischen Philologie 15), S. 191-207.

Glauser, Jürg, 'Romance (Translated riddarasögur)'. In: A Companion to Old Norse-Icelandic Literature and Culture. Hg. v. Rory Mc Turk. Oxford 2005, S. 372-387.

Glauser, Jürg (Hg.), Skandinavische Literaturgeschichte. 2. Aufl. Stuttgart, Weimar 2016. Holm, Gösta, 'Eufemiavisorna'. In: Medieval Scandinavia: An Encyclopedia. Hg. v. Philip Pulsiano. New York 1993, S. 171-173.

Horstbøll, Henrik, Menigmands medie. Det folkelige bogtryk i Danmark 1500-1840. København 1999 (Danish Humanist Texts and Studies 19).

Jacobsen, J.P. et al. (Hgg.), Danske Folkebøger fra 16. og 17. Aarhundrede. Bd. VI. København 1925.

Kalinke, Marianne E., 'Norse Romance (Riddarasögur)'. In: Carol J. Clover und John Lindow (Hgg.), Old Norse-Icelandic Literature. A Critical Guide. Toronto u.a. 2005, S. 316-363.

Kalinke, Marianne E., 'Scribe, Redactor, Author: The Emergence and Evolution of Icelandic Romance'. In: Viking and Medieval Scandinavia 8 (2012), S. 171-198.

Kalinke, Marianne E., 'Clári saga, Hrólfs saga Gautrekssonar, and the Evolution of Icelandic Romance'. In: Riddarasogur. The Translation of European Court Culture in Medieval Scandinavia. Hg. v. Karl G. Johansson und Else Mundal. Oslo 2014, S. 273-292.

Lefevere, André, Translation, Rewriting and the Manipulation of Literary Fame. London, New York 1992.

Müller, Jan-Dirk, 'Volksbuch/Prosaroman im 15./16. Jahrhundert. Perspektiven der Forschung'. In: Internationales Archiv für Sozialgeschichte der Literatur 1 (1985), Sonderheft (Forschungsreferate), S. 1-128.

Nielsen, Lauritz, Dansk bibliografi: med saerligt hensyn til dansk bogtrykkerkunsts historie. 3 Bde. København 1919-1935.

Nyborg, Birgit (Hg.), Tre riddersagaer: Sagaen om Partalopi. Sagaen om Flores og Blankiflor. Sagaen om Bevers. Oslo 2005. 
Partalopa saga. Hg. v. Lise Præstgaard Andersen. Copenhagen 1983 (Editiones Arnamagnæanæ, Series B, 28).

Pulsiano, Phillip (Hg.), Medieval Scandinavia: An Encyclopedia. New York 1993.

Richter, Anna Katharina, Transmissionsgeschichten. Untersuchungen zur dänischen und schwedischen Erzählprosa in der frühen Neuzeit. Tübingen, Basel 2009 (Beiträge zur nordischen Philologie 41).

Richter, Anna Katharina, 'La transmission de Floire et Blancheflor au Danemark (XV'-XVII siecles)'. In: L'expérience des frontières et les littératures de l'Europe médiéval. $\mathrm{Hg}$. v. Sofia Lodén und Vanessa Obry. Paris 2019 (Colloques, Congrès et Confèrences - Le Moyen Âge, 26, 1 vol.) (in Vorbereitung).

Rikhardsdottir, Sif, Medieval Translations and Cultural Discourse. The Movement of Texts in England, France and Scandinavia. Cambridge 2012.

Le Roman de Partonopeu de Blois. Édition, traduction et introduction de la rédaction A (Paris, Bibliothèque de l'Arsenal, 2986) et de la Continuation du récit d'après les manuscrits de Berne (Burgerbibliothek, 113) et de Tours (Bibliothèque municipale, 939), par Olivier Collet et Pierre-Marie Joris. Paris 2005.

Würth, Stefanie, 'Eufemia. Deutsche Auftraggeberin schwedischer Literatur am norwegischen Hof'. In: Arbeiten zur Skandinavistik. 13. Arbeitstagung der deutschsprachigen

Skandinavistik 29. 7.-3.8.1997 in Lysebu/Oslo. Hg. v. Fritz Paul. Frankfurt a.M. 2000 (Texte und Untersuchungen zur Germanistik und Skandinavistik 45), S. 269-281.

Zumthor, Paul, Toward a Medieval Poetics. Übers. von Philip Bennett. Minneapolis 1992. 